\title{
Genitals evolve faster than other traits in Anolis lizards
}

\section{Citation}

Klaczko, J., T. Ingram, and J. Losos. 2015. “Genitals Evolve Faster Than Other Traits in Anolis lizards." Journal of Zoology 295 (1) (January): 44-48. doi:10.1111/jzo.12178.

\section{Published Version}

doi:10.1111/jzo.12178

\section{Permanent link}

http://nrs.harvard.edu/urn-3:HUL.InstRepos:34309459

\section{Terms of Use}

This article was downloaded from Harvard University's DASH repository, and is made available under the terms and conditions applicable to Open Access Policy Articles, as set forth at http:// nrs.harvard.edu/urn-3:HUL.InstRepos:dash.current.terms-of-use\#OAP

\section{Share Your Story}

The Harvard community has made this article openly available.

Please share how this access benefits you. Submit a story.

Accessibility 
Genitals evolve faster than other traits in Anolis lizards

Julia Klaczko $^{1,2 *}$, Travis Ingram ${ }^{1,3}$, and Jonathan Losos ${ }^{1}$

${ }^{1}$ Museum of Comparative Zoology and Department of Organismic and Evolutionary Biology, Harvard University, Cambridge, USA.

${ }^{2}$ Departamento de Biologia Animal, Instituto de Biologia, Universidade Estadual de Campinas, UNICAMP, Cx. Postal 6109, Campinas, SP, Brazil

3 Department of Zoology, University of Otago, 340 Great King Street, Dunedin, New Zealand.

*Corresponding author.E-mail: jklaczko@harvard.fas.edu

Summary

Male genitalia are thought to be particularly rapidly evolving morphological structures, but there have been few quantitative interspecific comparisons between the evolutionary rates of genital and non-genital traits. We characterize the morphology of hemipenes in 25 Caribbean Anolis lizard species, and compare rates of hemipenial evolution to those of traits related to ecology or visual signaling. Using phylogenetically-based comparisons of rates of evolutionary divergence, we show that genital traits evolve more rapidly than non-genital traits in anoles.

Keywords: phylogenetic comparative methods, hemipenis, brownian motion, ecomorphology .

\section{Introduction}

The male genitalia of animals with internal fertilization are complex morphological traits that are thought to evolve rapidly (Eberhard, 1985). The tendency for closely related species to differ in genital morphology has led to both the use of genitalia as a key taxonomic character, and to the suggestion that male genital traits have especially high rates of evolution compared to other traits (Eberhard, 2009; Rowe \& Arnqvist, 2011). However, this conclusion is based mainly on qualitative descriptions of differences between closely related species rather than quantitative analysis of evolutionary rates. A study of fifteen water strider species showed that genital traits have greater complexity than non-genital traits (Rowe \& Arnqvist, 2011). However, to our knowledge, no phylogenetic comparative study has explicitly compared the rates of evolution of genital and non-genital traits.

The rapidity of genital trait evolution, if it is real, this may be explained by a number of factors. The most prominent hypothesis for why genitalia evolve rapidly is sexual 
selection (Arnqvist, 1997; Eberhard, 2010). Sexual selection may drive rapid male genital evolution either through cryptic female choice or sexually antagonistic coevolution, both of which predict the rapid evolution of male genitalia as a result of coevolution with the female. Cryptic female choice may favor male genitalia that better fit or stimulate the female, while sexually antagonistic coevolution occurs if male genitalia evolve to reduce female control of reproduction, leading to a coevolutionary arms race between the sexes (reviewed in Hosken \& Stockley, 2004).

The male genitalia of squamate reptiles, termed "hemipenes," consist of a pair of intromittent tubular structures. Each hemipenis surface contains a groove, the sulcus spermaticus, through which semen is conducted. Their shape varies from cylindrical tubes to deeply bilobed structures, ornamented with calyces, papillae, flounces, and spines. As hemipenial morphology varies extensively among squamate taxa it has been used extensively in systematic studies (Arnold, 1983; 1986a; Nunes et al., 2012; Köhler et al., 2012). However, comparative studies at larger taxonomic scales are rare in lizards (e.g. Arnold, 1986b), and evolutionary analyses of diversification rates are lacking.

Caribbean Anolis lizards are a model system for the study of adaptive radiation, as they exhibit high rates of speciation and ecological and morphological diversification (Losos, 2009 Anoles show repeated convergence in ecomorphological traits across the islands of the Greater Antilles (Cuba, Hispaniola, Jamaica, and Puerto Rico). Similar sets of microhabitat specialists, termed ecomorphs, have independently evolved similar morphologies, behaviors, and sexual dimorphism on each island (Williams 1972, Losos 2009, Mahler et al 2013). Limb length is a particularly important element of ecomorphology, as it determines species' locomotory performance on perches of different diameters in different parts of the vegetation (Losos 1990). Anoles are also characterized by a prominent dewlap, an extendible and usually colorful flap of skin under the throat that is used in social signaling and considered important to species recognition (Glor \& Laport, 2012; Harrison \& Poe, 2012; reviewed in Losos, 2009). Anoles are therefore an ideal system in which to examine the evolutionary dynamics of hemipenes, as rates of evolution can be compared directly between genital traits and non-genital traits known to be related to ecological diversification and social interaction. The available studies on anole hemipenial morphology focus on variation among small numbers of closely related species (i.e, Köhler, Dehling, \& Köhler, 2010; Köhler, 2011; Köhler et al., 2012; Klaczko \& Stuart, in review). Here we present the first substantial study of anole hemipenes, using quantitative measurements to describe variation in genital morphology across the Greater Antilles.

We quantify hemipenial morphology of 25 ecologically diverse species of Caribbean Anolis. We use phylogenetic comparative methods to estimate the evolutionary rates of hemipenial traits, and to test whether they exceed the evolutionary rate of morphological traits related to microhabitat (limbs) and signaling (dewlaps).

\section{Material and Methods}

Taxon sampling and morphological measurements

We examined the male genitalia and body morphology of 25 Anolis species representing the diversity of microhabitat specialists present in Caribbean anoles. We measured on average five specimens per species, with a range of 1-30 (Supplementary Material I). We 
used fresh specimens when available, as well as preserved museum specimens. One of the hemipenes was dissected from the specimen through a small incision at the base of the tail. The removed hemipenis was immersed in a $2 \% \mathrm{KOH}$ solution for 3-5 min, or until it became translucent and flexible. Once flexible, the hemipenis was everted manually using forceps, ensuring that all specimens were completely everted. The fully everted organ was filled with colored vaseline to allow better visualization of ornamentation structures. We obtained digital images of hemipenes in the face containing the sulcus spermaticus using a JVC camera KYF75U attached to a stereomicroscope with the aid of Auto-Montage Pro, 5.02.

We took three hemipenial measurements: total length, width at the lobes, and width at the hemipenial body (Fig. 1E). These measurements were obtained from the digitized images using the software ImageJ 1.46r. We traced a line across the apex of the lobes and measured hemipenial length as the distance between this line and the base of the hemipenis. The width at the hemipenial lobes was obtained by measuring the widest region of the lobes, and width at the hemipenial body was obtained by measuring the width approximately halfway along the body of the hemipenis.

We also used a digital caliper to measure three non-genital traits on the same specimens: limb lengths (thigh and shank) and dewlap length. Thigh length was measured ventrally from the insertion point of the head of the thigh to the knee. The shank length was measured dorsally. The length of the dewlap was measured from the second arc ceratobranchial of the hyoid. The final portion of the second arc ceratobranchial cartilage was exposed thru a small incision at the base of the dewlap, and the measure was obtained from the snout to the end of the cartilage Finally, we used snout-vent length (SVL) as a measure of body size. We measured all traits twice and estimated the repeatability of the measurements using the intra class coefficient (ICC) as described by Lessells \& Boag (1987) and implemented in the ICC package (Wolak, 2012) in the R environment (R Core Team, 2013). For the subsequent statistical analysis we used the mean of both measurements.

For each trait we performed a log-log regression of species mean trait measurements on species mean SVL. The residuals from these regressions were used as size corrected measures of trait values for the evolutionary rate analyses. These and all following statistical analyses were performed in the R environment (R Core Team, 2013). For comparative analyses that account for species' phylogenetic relationships, we used the maximum clade credibility phylogenetic tree from a Bayesian analysis of mitochondrial DNA of 187 Anolis species (Mahler et al., 2010). We rescaled the tree to a total depth of 1.0, and pruned it to include only the 25 species measured for this study. We assessed whether size-corrected traits show a signal of phylogeny (a statistical association between trait values and relatedness) using Blomberg's K statistic (Blomberg, Garland, \& Ives, 2003). This statistic can indicate little or no phylogenetic signal $(\mathrm{K}<<$ $1)$, or phylogenetic signal equal to $(K \approx 1)$ or greater than $(K>>1)$ the expectation under a Brownian motion random-walk model of evolution. To test if the traits we measured contain a signal of phylogeny (i.e. $\mathrm{K}>0$ ), we randomly permuted the order of species on the tree 1000 times and recalculated $\mathrm{K}$ for each permutation. We then compared the observed $\mathrm{K}$ value to this null distribution to assess significance. 
To test whether the hemipenial traits evolve faster than the non-genital traits, we used Adams' (2012) likelihood method for comparing evolutionary rates of different phenotypic traits. This method estimates the rate of evolution as the Brownian rate parameter $\sigma^{2}$, and compares the fit of models in which traits differ in rates versus being constrained to share rates. We fit three models, starting with a 'free' model in which each of the six size-corrected traits was allowed to take its own rate. Second, we fit a 'singlerate' model in which all traits are constrained to share one rate. Finally, we fit a 'grouped' model in which the three genital traits share one rate and the three non-genital traits share a second rate. We used likelihood ratio tests to compare nested models, and calculated the finite sample size-corrected Akaike Information Criterion and Akaike weights to measure the support for each model (Burnham and Anderson, 2002). We visualized rate variation by comparing the Euclidean distances between species for each set of traits (hemipenes, limbs, and dewlaps) to their phylogenetic distances (Arnegard et al., 2010).

\section{Results}

Measurements of all traits were highly repeatable: dewlap size $(\mathrm{ICC}=0.98)$, femur (ICC $=0.91)$, metatarsus $(\mathrm{ICC}=0.90)$, hemipenis length $(\mathrm{ICC}=0.97)$, hemipenis width at lobe $(\mathrm{ICC}=0.99)$, and hemipenis width at body $(\mathrm{ICC}=0.98$; all $\mathrm{P}<0.001)$. Most traits were phylogenetically structured (Blomberg's $\mathrm{K}>0$; Table 1), though phylogenetic signal was lower for hemipenial than for non-hemipenial traits. $\mathrm{K}$ was significantly greater than zero for only one of three hemipenial traits (and for all three non-hemipenial traits). See the supplementary material (Supplementary Material II) for descriptive statistics for hemipenial and non-genital traits.

Evolutionary rate analysis showed strong support for rate variation among traits, with genital traits estimated to have a rate six times higher than non-genital traits (Table 1). The single-rate model fit much more poorly than either the free or grouped models (Likelihood ratio tests; free $v s$. single-rate: ${ }^{2}=60.7$, d.f. $=4, p<0.001$; grouped $v s$. single-rate: ${ }^{2}=$, d.f. $=1, p<0.001$ ), while the free model did not offer sufficient improvement in fit over the grouped model to support a separate rate for each trait $\left(^{2}=\right.$ 7.0 , d.f. $=3, p=0.13$ ). This finding was corroborated by the $\mathrm{AIC}_{\mathrm{c}}$ values, which showed that the grouped model in which genital and non-genital traits evolve at different rates strongly outperformed the other two models (single-rate: $\mathrm{AIC}_{\mathrm{c}}=18.0$; free: $\mathrm{AIC}_{\mathrm{c}}=$ 49.3), and received almost all support by Akaike weights $\left(w_{A}>0.999\right)$. Comparison of Euclidean trait distances to phylogenetic distances confirmed that hemipenial traits diverge more rapidly over time than non-genital traits (Fig. 2).

\section{Discussion}

Our results provide quantitative support for the common presumption that male genitalia are more variable and evolve more rapidly than non-genital morphological traits (Eberhard, 2009; Eberhard, 2010; Arnqvist, 1997; Hosken \& Stockley, 2004). While this conclusion has previously been drawn largely from the fact that genitalia tend to be species-specific and diagnostic of otherwise cryptic species, (Eberhard, 2010, Böhme \& Ziegler, 2009), we corroborate it using modern phylogenetic comparative analyses across a diverse genus. We found that in Caribbean anoles, hemipenial traits evolve 
approximately six times faster than non-genital traits (Table 1, and 2), with the three genital traits sharing a similar and high rate.

These high rates of hemipenial trait evolution could be explained by sexual selection. Characters likely to be under sexual selection (such as signaling traits) are expected to evolve more rapidly, especially when these traits are relatively unconstrained by ecology and linked to reproductive isolation (Arnegard et al., 2010). Explanations of male genitalia evolution that invoke sexual selection comprise two hypotheses: cryptic female choice, and sexually antagonistic coevolution. The cryptic female choice hypothesis suggests that females favor some males over others, as a result of a better fit with female genitals or more effective stimulation of the female (Eberhard, 2010). On the other hand, sexually antagonistic coevolution suggests that the evolution of male genitalia results from an evolutionary arm race between males and females for control over reproduction (Arnqvist \& Rowe, 2002). Distinguishing between these hypothesis is a difficult task, since sexually antagonistic coevolution is a particular case of the broad hypothesis of cryptic female choice, and in fact, sexual conflict includes female choice as a key component (Rowe \& Arnqvist, 2011).

Further investigations into hemipenial evolution are needed to clarify the causes and consequences of high rates of morphological evolution in Anolis hemipenes. Future studies should examine relationships between hemipenial size and shape and measures of mating system and ecological adaptation across a greater diversity of species. Importantly, due in part to methodological challenges, female genitalia in squamates has historically been rarely studied (Köhler et al., 2012). Future comparative studies that measure female genitalia and analyze their coevolution with hemipenes should shed new light on the evolution of squamate genitalia (Ah-King, Barron, \& Herberstein, 2014). While the causes of genital evolution remain to be determined, the rapid rate at which hemipenes diversify is now clear. Anoles are famous for their high rates of diversification of ecologically-relevant morphology, and the fact that their genitals nonetheless evolve far more rapidly than other traits speaks to the significance of genital diversification in animal evolution.

\section{Acknowledgments}

We thank Dr. G. Köhler, and an anonymous reviewer for the helpful comments that improve the manuscript. This work was supported by a research fellowship from Fundação de Amparo à Pesquisa do Estado de São Paulo (FAPESP), and a research fellowship from the Conselho Nacional de Desenvolvimento Científico e Tecnológico (CNPq).

\section{References}

Adams, D. C. (2012). Comparing evolutionary rates for different phenotypic traits on a phylogeny using likelihood. Systematic Biology 62, 181-192.

Ah-King, M., Barron, A. B., \& Herberstein, M. E. (2014). Genital evolution: why are females still understudied? PLoS biology, 12: e1001851.

Arnegard, M. E., McIntyre, P. B., Harmon, L. J., Zelditch, M. L., Crampton, W. G. R., Davis, J. K., Sullivan, J. P., Lavoué, S., \& Hopkins, C. D. (2010). Sexual signal evolution outpaces ecological divergence during electric fish species radiation. The American Naturalist 176, 335-356. 
Arnold, E. N. (1986a). The hemipenis of lacertid lizards (Reptilia: Lacertidae): structure, variation and systematic implications. Journal of Natural History 20, 1221-1257.

Arnold, E. N. (1986b). Why copulatory organs provide so many useful taxonomic characters: the origin and maintenance of hemipenial differences in lacertid lizards (Reptilia: Lacertidae). Biological Journal of the Linnean Society 29, 263-281. Arnqvist, G. (1997). The evolution of animal genitalia: distinguishing between hypotheses by single species studies. Biological Journal of the Linnean Society 60, 365-379.

Arnqvist, G., \& Rowe, L. (2002). Correlated evolution of male and female morphologies in water striders. Evolution 56, 936-947.

Blomberg, S. P., Garland, T., \& Ives, A. R. (2003). Testing for phylogenetic signal in comparative data: behavioral traits are more labile. Evolution, 57, 717-745.

Böhme, W., \& Ziegler, T. (2009). A review of iguanian and anguimorph lizard genitalia (Squamata: Chamaeleonidae; Varanoidea, Shinisauridae, Xenosauridae, Anguidae) and their phylogenetic significance: comparisons with molecular data sets. Journal of Zoological Systematics and Evolutionary Research 47, 189-202. Burnham, K. P., \& Anderson, D. R. (2002). Model selection and multimodel inference: a practical information-theoretic approach. New York, NY: Springer. Eberhard, W. G. (1985). Sexual selection and animal genitalia. Harvard University Press.

Eberhard, W. G. (2009). Evolution of genitalia: theories, evidence, and new directions. Genetica 138, 5-18.

Eberhard, W.G. (2010). Rapid divergent evolution of genitalia. In Leonard JL, Córdoba-Aguilar A, eds. The evolution of primary sexual characters in animals. Oxford, UK: Oxford University Press .

Hosken, D. J., \& Stockley, P. (2004). Sexual selection and genital evolution. Trends in Ecology \& Evolution 19, 87-93.

Klaczko, J., \& Stuart, Y. in revision. Hemipenial allometry in Anolis grahami. Köhler, G. (2011). A new species of anole related to Anolis altae from Volcán Tenorio, Costa Rica (Reptilia, Squamata, Polychrotidae). Zootaxa 3120, 29-42. Köhler, G., Dehling, D. M., \& Köhler, J. (2010). Cryptic species and hybridization in the Anolis polylepis complex, with the description of a new species from the Osa Peninsula, Costa Rica (Squamata: Polychrotidae). Zootaxa 2718, 23-38.

Köhler, J., Hahn, M., \& G. Köhler (2012). Divergent evolution of hemipenial morphology in two cryptic species of mainland anoles related to Anolis polylepis. Salamandra 48, 1-11.

Losos, J.B. (1990). Ecomorphology, performance capability, and scaling of West Indian Anolis lizards: an evolutionary analysis. Ecological Monographs 60, 369-388.

Losos, J.B. (2009). Lizards in an evolutionary tree: ecology and adaptive radiation of anoles. Berkeley, CA: University of California Press.

Mahler, D. L., Ingram, T., Revell, L. J., \& Losos, J. B. (2013). Exceptional convergence on the macroevolutionary landscape in island lizard radiations. Science 341, 292-295.

Mahler, D. L., Revell, L. J., Glor, R. E., \& Losos, J. B. (2010). Ecological opportunity and the rate of morphological evolution in the diversification of Greater Antillean Anoles. Evolution 64, 2731-2745. 
R Core Team. (2013). R: A language and environment for statistical computing. $R$ Foundation for Statistical Computing, Vienna, Austria.

Rowe, L., \& Arnqvist, G. (2011). Sexual selection and the evolution of genital shape and complexity in water striders. Evolution 66, 40-54.

\section{Tables}

Table 1. Phylogenetic signal and evolutionary rates estimated for each trait under the three models of rate variation.

\begin{tabular}{|c|c|c|c|c|c|}
\hline & $\mathbf{K}$ & $P$ & $e^{\sigma_{f r e}^{2}}$ & $\sigma_{\text {grouped }}^{2}$ & $\begin{array}{l}\sigma_{\text {single- }}^{2} \\
\text { rate }\end{array}$ \\
\hline Dewlap & 0.77 & 0.016 & 0.0065 & 0.0044 & 0.0156 \\
\hline Thigh & 0.95 & 0.002 & 0.0030 & 0.0044 & 0.0156 \\
\hline Shank & 1.02 & 0.002 & 0.0039 & 0.0044 & 0.0156 \\
\hline $\begin{array}{l}\text { Hemipenis } \\
\text { length }\end{array}$ & 0.61 & 0.089 & 0.0180 & 0.0268 & 0.0156 \\
\hline $\begin{array}{l}\text { Hemipenis } \\
\text { width at } \\
\text { lobes }\end{array}$ & 0.66 & 0.034 & 0.0366 & 0.0268 & 0.0156 \\
\hline $\begin{array}{l}\text { Hemipenis } \\
\text { width at } \\
\text { body }\end{array}$ & 0.60 & 0.110 & 0.0257 & 0.0268 & 0.0156 \\
\hline
\end{tabular}

\section{Figure legends}

Figure 1: (A-E) Hemipenial morphological variation: (A) Anolis litoralis MCZA 29333; (B) A. evermani MCZR137728; (C) A. brunneus JASIL 2848; (D) A. cybotes MCZA33061; and (E) A. grahami MCZA24502, also used to illustrate hemipenial measurements (1: length; 2: width at the lobes; 3: width at the body). Scale bar $=1 \mathrm{~mm}$.

Figure 2: Rates of trait divergence measured across Anolis species. Euclidean distances between species are larger over shorter evolutionary timescales for hemipenial traits than for limbs or dewlaps. 